\title{
SCREENING METHOD FOR DEXTRANASES AND AMYLODEXTRANASES FROM ANAEROBIC THERMOPHILES
}

\author{
CORAL WYNTER \\ Department of Biochemistry, University of Queensland, St. Lucia, Qld, 4072 Australia
}

(Received November 21, 1995; Accepted April 12, 1996)

Currently, there is no suitable method for screening thermophilic bacteria for dextranases (E.C. 3.2.1.11). Here we report a procedure suitable for the identification of anaerobes grown at high temperatures $\left(55-68^{\circ} \mathrm{C}\right)$. Water samples to be screened are inoculated into liquid medium containing Blue Dextran. Anaerobic thermophiles containing an active dextranase can be identified visually by a change in color of the medium from blue to yellow. The method may be quantified by extracting the cell-free supernatant into 70\% ethanol and measuring absorbance at $420 \mathrm{~nm}$. Production of the yellow chromophore requires actively growing cells producing an endodextranase. Some 150 thermophiles were screened. A selection of 30 anaerobic thermophiles were ranked with respect to their dextranase activity. This method allowed the identification of organisms producing a new class of enzyme, amylodextranase, which hydrolyses both starch and dextran.

Dextranases (1,6- $\alpha$-D-glucan-6-glucanohydrolase; E.C. 3.2.1.11) hydrolyse the internal 1,6- $\alpha$-D-glucosidic bonds of dextran. The enzyme has been found in bacteria such as Streptococcus, Bacillus, Cellvibrio, Flavobacterium, Arthrobacter, Lactobacillus and Bacteroides $(3,10)$ and in fungi such as Pencillium, Lipomyces, Aspergillus and Chaetomium. The level of dextranase activity produced by fungi is usually much higher than bacteria (13).

The role of dextranases secreted by oral Streptococcus mutans in preventing plaque formation on the surface of human teeth has been the subject of many investigations (5). Dextranases have also been used in the sugar industry to remove contaminating dextrans produced by infection of raw sugar cane with Leuconostoc mesenteroides, Lactobacillus and other dextran-forming bacteria (4). Dextranase from Chaetomium gracile is currently used to remove dextrans present in deterio-

Present address and address reprint requests to: Dr. Coral Wynter, Department of Surgery, Greenslopes Private Hospital, Newdegate St., Greenslopes, Queensland, 4120 Australia. 
rated sugar cane juice (6). However the Chaetomium dextranase rapidly loses activity at the operating temperature of the incubators $\left(75^{\circ} \mathrm{C}\right)$. Since the Chaetomium enzyme had the best thermostability of available commercial dextrans, a search was instigated for an enzyme with improved thermostability. This required an efficient screening method to detect dextranase activity from thermophilic bacteria.

Most microbial screening and assay methods for dextranase have been based on the use of the dye Blue Dextran (7). Blue Dextran contains the dye Cibacron Blue linked through hydroxyl groups to glucose units in the polysaccharide chain. Bacteria growing on agar plates with medium incorporating Blue Dextran produce a clear white zone around the colony if they secrete an active dextranase. This method was first used to screen microorganisms on agar plates, using Blue Dextran as the sole carbon source (9). However it was not successful with thermophilic bacteria because Blue Dextran moves within the gel along with water as it evaporates, leaving artificial clear patches. Here we report on a modification of the Blue Dextran method to detect and quantify dextranase activity in anaerobic thermophiles.

\section{MATERIALS AND METHODS}

Materials. Blue Dextran 2000, Dextran T2000 and Blue Trisacryl were supplied by Pharmacia Fine Chemicals, Uppsala, Sweden. p-Hydroxybenzoic acid hydrazide (PAHBAH) and Cibacron Blue 3GA were obtained from Sigma, Sydney, Australia. Tryptone, yeast extract and Bacteriological Agar No. 1 were supplied by Oxoid, Melbourne, Australia.

Bacterial strains. Water samples from 16 flowing non-volcanic thermal bore holes in the Australian Artesian Basin in Western Queensland were collected by filling sterile Universal glass bottles. Other samples from the same bore hole were collected at various points in the runoff channel. Temperatures of the samples ranged from 32 to $88^{\circ} \mathrm{C}$. The samples were stored at ambient temperature. The same techniques were used to collect samples from hot springs at Rotorua, New Zealand and in Fiji and India.

Media. Cells were grown anaerobically at $68^{\circ} \mathrm{C}$ in Hungate tubes containing $10 \mathrm{ml}$ of Low Phosphate Buffered Mineral Salts (LPBMS) medium, containing in $1 l$ of distilled water: $\mathrm{NH}_{4} \mathrm{Cl}, 0.9 \mathrm{~g} ; \mathrm{MgCl}_{2}, 0.2 \mathrm{~g} ; \mathrm{KH}_{2} \mathrm{PO}_{4}, 0.75 \mathrm{~g} ; \mathrm{K}_{2} \mathrm{HPO}_{4}, 1.5 \mathrm{~g}$; Zeikus trace element solution, $9 \mathrm{ml} ; 10 \% \mathrm{FeSO}_{4}, 30 \mu \mathrm{l} ; 10 \%$ resazurin, $1 \mathrm{ml}$. The Zeikus trace element solution (15) contained in $1 l$ of distilled water: nitrilotriacetic acid, $12.8 \mathrm{~g} ; \mathrm{KOH}, 8.6 \mathrm{~g} ; \mathrm{FeCl}_{3} \cdot 4 \mathrm{H}_{2} \mathrm{O}, 0.2 \mathrm{~g} ; \mathrm{MnCl}_{2} \cdot 4 \mathrm{H}_{2} \mathrm{O}, 0.1 \mathrm{~g} ; \mathrm{CoCl}_{2} \cdot 6 \mathrm{H}_{2} \mathrm{O}$, $0.17 \mathrm{~g} ; \mathrm{CaCl}_{2} \cdot 2 \mathrm{H}_{2} \mathrm{O}, 0.1 \mathrm{~g} ; \mathrm{ZnCl}_{2}, 0.1 \mathrm{~g} ; \mathrm{CuCl}_{2}, 0.02 \mathrm{~g} ; \mathrm{H}_{3} \mathrm{BO}_{3}, 0.01 \mathrm{~g} ; \mathrm{NaMoO}_{4} \cdot$ $2 \mathrm{H}_{2} \mathrm{O}, 0.01 \mathrm{~g} ; \mathrm{NaCl}, 1.0 \mathrm{~g} ; \mathrm{Na}_{2} \mathrm{SeO}_{3}, 0.02 \mathrm{~g}$; and adjusted to $\mathrm{pH} 7.0$ with $\mathrm{KOH}$. The LPBMS medium was fortified with $0.2 \%$ tryptone, $0.1 \%$ yeast extract and $0.5 \%$ Dextran T2000 (designated TYED). Medium made with Blue Dextran (0.5\%) in place of Dextran T2000 contained no resazurin and is referred to as liquid Blue 
Dextran medium (TYEBD). Anaerobic Blue Dextran agar (BDA) plates, containing 2.5\% agar made in TYEBD medium, were poured in a Fretner-type flexible anaerobic chamber and incubated at $68^{\circ} \mathrm{C}$. Growth was monitored by the increase in turbidity at $660 \mathrm{~nm}$ by insertion of the Hungate culture tube directly into a Spectronic 20 (Bausch and Lomb, NY, U.S.A.).

Aerobic organisms from thermal water samples were enriched by inoculation into $10 \mathrm{ml}$ of Castenholz Medium D (2). This contained in $1 l$ of distilled water: $0.5 \%$ Blue Dextran, $0.05 \%$ yeast extract, $0.05 \%$ tryptone and $50 \mathrm{ml}$ of Castenholz mineral salts. The latter contained in $1 l$ of distilled water: nitrilotriacetic acid, $2 \mathrm{~g}$; $\mathrm{CaSO}_{4} \cdot 2 \mathrm{H}_{2} \mathrm{O}, 1.2 \mathrm{~g} ; \mathrm{MgSO}_{4} \cdot 7 \mathrm{H}_{2} \mathrm{O}, 2 \mathrm{~g} ; \mathrm{NaCl}, 0.16 \mathrm{~g} ; \mathrm{KNO}_{3}, 2 \mathrm{~g} ; \mathrm{NaNO}_{3}, 13.78 \mathrm{~g}$; $\mathrm{Na}_{2} \mathrm{HPO}_{4}, 2.2 \mathrm{~g} ; \mathrm{FeCl}_{3}, 0.0058 \mathrm{~g}$; and micronutrient solution, $20 \mathrm{ml}$. The $\mathrm{pH}$ was adjusted to 3 and stored after autoclaving at $4{ }^{\circ} \mathrm{C}$. The micronutrient solution contained in $1 l$ of distilled water: conc $\mathrm{H}_{2} \mathrm{SO}_{4}, 0.5 \mathrm{ml} ; \mathrm{MnSO}_{4} \cdot \mathrm{H}_{2} \mathrm{O}, 2.28 \mathrm{~g}$; $\mathrm{ZnSO}_{4}$. $7 \mathrm{H}_{2} \mathrm{O}, 0.5 \mathrm{~g} ; \mathrm{H}_{3} \mathrm{BO}_{3}, 0.5 \mathrm{~g} ; \mathrm{CuSO}_{4} \cdot 5 \mathrm{H}_{2} \mathrm{O}, 0.025 \mathrm{~g} ; \mathrm{Na}_{2} \mathrm{MoO}_{4} \cdot 2 \mathrm{H}_{2} \mathrm{O}, 0.025 \mathrm{~g} ; \mathrm{CoCl}_{2}$. $6 \mathrm{H}_{2} \mathrm{O}, 0.045 \mathrm{~g}$. Cultures were incubated in sealed $20-\mathrm{ml} \mathrm{McCartney} \mathrm{bottles} \mathrm{at} 55^{\circ} \mathrm{C}$.

Isolation of strains. Dextranase-producing isolates from water samples were purified by subculturing three times on TYED, by serial dilution in TYEBD or on BDA plates at $68^{\circ} \mathrm{C}$. Strains Rt56 and AB11A were purified on BDA plates while strain Rt463 was purified by serial dilution (14). Morphology and motility of cells was examined in wet mounts under phase-contrast microscopy.

Screening of anaerobic thermophiles. Screening was normally performed on thermal water samples as soon as possible after collection. Samples $(0.1-0.5 \mathrm{ml})$ were inoculated in $10 \mathrm{ml}$ of TYEBD in Hungate tubes and incubated at $68^{\circ} \mathrm{C}$ for 7 days. When purified strains were screened, they were grown in TYED at $68^{\circ} \mathrm{C}$ and an aliquot $(0.1 \mathrm{ml})$ at the midpoint of the $\log$ phase of growth was used for inoculating into TYEBD $(10 \mathrm{ml})$. In anaerobic cultures, the presence of dextranase resulted in a progressive color change of the medium from blue to green to orange or yellow. For quantitative analysis, samples were subcultured into fresh TYEBD media $(10 \mathrm{ml})$ and incubated at $68^{\circ} \mathrm{C}$. Aliquots $(0.5 \mathrm{ml})$ were withdrawn after 1 , 2,3 and 7 days growth. The cells were removed by centrifugation and unhydrolysed Blue Dextran was precipitated by adding two volumes of ethanol. Low molecular weight degraded Blue Dextran remained in solution. After $30 \mathrm{~min}$ on ice, the samples were centrifuged $(12,000 \times g, 5 \mathrm{~min})$. The absorbance of the yellow chromophore in the supernatant was measured at $420 \mathrm{~nm}$ within $30 \mathrm{~min}$ on a Hitachi U2000 spectrophotometer. A blank value was obtained by treating a sample of the uninoculated medium with $70 \%$ ethanol and the absorbance was measured as for the inoculated samples. The increase in absorbance at $420 \mathrm{~nm}$ for anaerobes gave an indication of the activity of dextranase produced by the bacterium.

Growth experiments on Cibacron Blue. In order to determine whether the color change required the presence of actively growing cells, thermophilic strain Rt56 was grown on TYEBD for 7 days at $68^{\circ} \mathrm{C}$. The medium was sterilised by filtering through a $0.2-\mu \mathrm{m}$ filter in the anaerobic chamber. A sterile solution of 
Cibacron Blue (final concentration 0.5\%) was injected into the spent yellow medium. This was again incubated at $68^{\circ} \mathrm{C}$ for 7 days. A sample $(0.5 \mathrm{ml})$ was withdrawn and the absorbance of the yellow chromophore was measured at $420 \mathrm{~nm}$ as described above.

In order to define further the conditions required for observation of the color change, cells were grown on a range of media (See Results, Table 1). Thermophilic strain Rt364 which had been previously shown to produce the highest level of dextranase (14) was grown for 2 days in a 100-ml specimen bottle in 1\% tryptone, $0.3 \%$ yeast extract and $0.5 \%$ Dextran T2000 in LPBMS to a cell density of 0.35 at $A_{660}$. The cells were concentrated by centrifugation, washed with sterile anaerobic buffer (LPBMS) and resuspended in the same buffer $(7 \mathrm{ml})$. The concentrated cells $(1 \mathrm{ml})$ were inoculated into $10 \mathrm{ml}$ of the following media: tube 1 (control) contained TYEBD; tube 2 contained LPBMS, 0.3\% yeast extract, 1\% tryptone and $0.5 \%(\mathrm{w} / \mathrm{v})$ Cibacron Blue but no dextran; tube 3 contained LPBMS and 0.5\% (w/v) Cibacron Blue; tube 4 contained LPBMS and 0.5\% (w/v) Blue Dextran and tube 5 contained TYED and $0.5 \%(\mathrm{w} / \mathrm{v})$ Blue Trisacryl. An aliquot of the concentrated cells $(2 \mathrm{ml})$ was autoclaved for $30 \mathrm{~min}$ and $1 \mathrm{ml}$ was inoculated into TYEBD $(10 \mathrm{ml})$ and another $1 \mathrm{ml}$ inoculated into LPBMS $(10 \mathrm{ml})$ containing $0.5 \%$ $(\mathrm{w} / \mathrm{v})$ Cibacron Blue. After 2 days incubation at $68^{\circ} \mathrm{C}, 0.5 \mathrm{ml}$ was withdrawn from each tube, treated with $70 \%$ ethanol as above and the absorbance of the resulting chromophores measured at 630 and $420 \mathrm{~nm}$.

Assays. Dextranase activity in cell-free extracts was measured by the PAHBAH method based on a modification of the procedure of Lever (8) and Wynter et al. (14). Cell-free extracts were prepared by centrifuging at $12,000 \times g$ for $5 \mathrm{~min}$ and assaying the supernatant. The assay measures both endo- and exo-activity of the enzyme. After incubation of the sample with substrate dextran $(0.4 \%)$ at $75^{\circ} \mathrm{C}$ for $30 \mathrm{~min}$, an aliquot $(0.1 \mathrm{ml})$ was removed and reacted with PAHBAH for $10 \mathrm{~min}$ at $100^{\circ} \mathrm{C}$. PAHBAH reacts with very low concentrations of reducing sugars to give a stable yellow color. The absorbance was measured at 420 $\mathrm{nm}$. A standard curve was constructed by reacting known concentrations of glucose with $\mathrm{PABHAB}$ under the same conditions as the assay and measuring absorbance at $420 \mathrm{~nm}$. Due to the presence of high concentrations of free sugars in the spent medium, the supernatant was dialysed overnight against $0.05 \mathrm{M}$ citrate buffer, $\mathrm{pH} 5.0$ before assay. One unit of dextranase activity is defined as the amount of enzyme producing $1 \mu \mathrm{mol}$ of reducing sugar per minute under the assay conditions.

\section{RESULTS AND DISCUSSION}

\section{Screening methods for anaerobes}

Microorganisms were initially screened by growth in dextran-enriched media (TYED). Out of 26 water samples screened, 25 showed some growth. However no dextranase could be assayed by the PAHBAH method in these samples. The same 
26 thermophiles were also screened by the production of a clear zone on anaerobic plates containing Blue Dextran (BDA). The BDA plates contained a high concentation of agar $(2.5 \%)$ as lower agar concentrations allowed the Blue Dextran to move within the gel together with water at the high temperatures $\left(68^{\circ} \mathrm{C}\right)$ used for incubation, leaving artificial patches of white clear zones. Nine organisms gave a clear zone on BDA plates.

Strain AB11A, a known dextranase producer (14) grew well on both systems. However another known dextranase producer, strain Rt364, did not grow on BDA plates, even after many attempts using fresh media. These results suggested that the dextran-enriched medium was not sufficiently selective as a screening method and that the BDA plates were too restrictive in that some thermophiles could not grow on the high concentrations of agar. So a new method for screening thermophiles for dextranase activity was sought.

\section{Screening on liquid Blue Dextran medium}

The Blue Dextran method for assaying dextranase (7) uses ethanol extraction of soluble blue dye fragments (Cibacron Blue) as the basis of the assay. A modification of this assay was used to screen for dextranase producers in liquid culture. A number of anaerobic thermophiles were grown in TYEBD at $68^{\circ} \mathrm{C}$ with the idea of extracting soluble blue dye fragments in ethanol after several days' growth and measuring the absorbance at $630 \mathrm{~nm}$. Surprisingly, incubation of the anaerobic thermophiles produced a series of color changes of the TYEBD from a dark blue, brown, green to grey to orange and finally a yellow chromophore. Cells with the most rapid growth produced the yellow chromophore in the shortest time. Preliminary screening of the same 26 water samples as above yielded 10 positive results. This now included strain Rt364 which had previously been lost on BDA plates. Thus, this procedure was further explored as a more comprehensive screening method than those using BDA plates or TYED.

\section{Absorbance characteristics of the chromophore}

After growth of the anaerobe, AB11A, on liquid Blue Dextran medium at $68^{\circ} \mathrm{C}$, unhyrolysed Blue Dextran was precipitated with $70 \%$ ethanol. The spectrum of the chromophore in the supernatant was examined at 2, 4 and 7 days growth. Two major peaks appeared at 420 and $400 \mathrm{~nm}$ with a minor peak at $455 \mathrm{~nm}$ but there was no peak at $630 \mathrm{~nm}$ i.e. the absorption peak of Cibacron Blue. The three peaks increased in size during growth of the organism over several days (Fig. 1). The absorbance of the peak at $420 \mathrm{~nm}$ was chosen as the most sensitive indicator of production of the yellow chromophore.

In $70 \%$ ethanol, on exposure to air, the yellow chromophore measured at 420 $\mathrm{nm}$, slowly faded until at $24 \mathrm{~h}$ it reached a value which was $\sim 30 \%$ of the initial absorbance. Similar results for a range of organisms were obtained. Thus, it was important to carry out measurements of the chromophore within $30 \mathrm{~min}$ to ensure uniformity of results. 


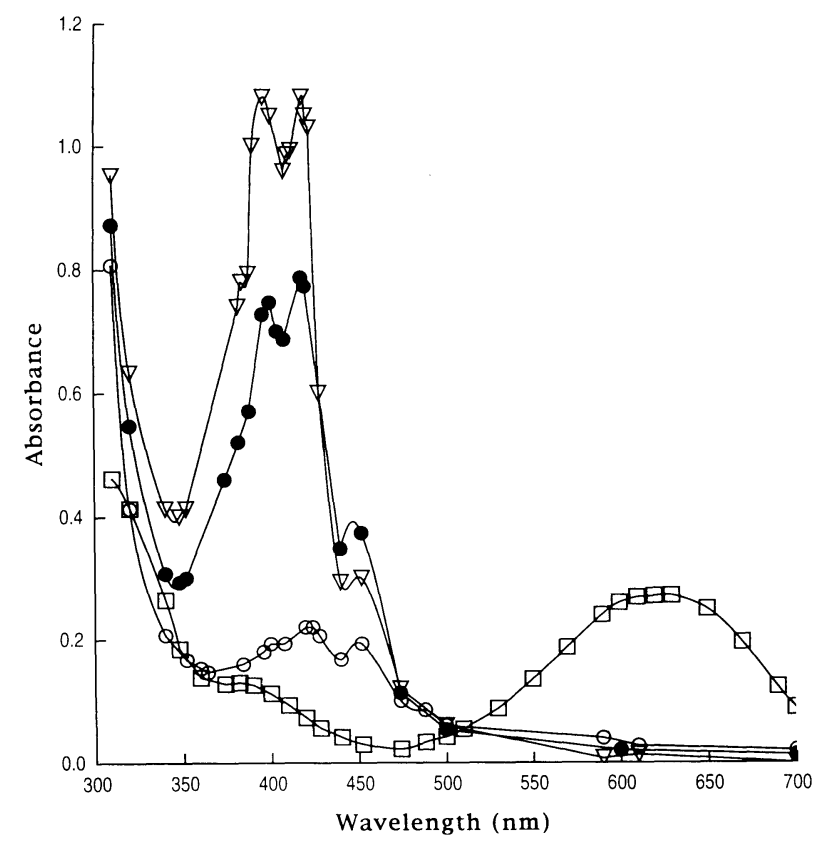

Fig. 1. Absorbance spectra of the chromophore, extracted into $70 \%$ ethanol from cultures of anaerobic thermophile, AB11A, after $2(\bigcirc), 4(\bullet)$ and 7 days $(\nabla)$ growth at $68^{\circ} \mathrm{C}$ in liquid Blue Dextran medium.

Absorbance spectrum of Cibacron Blue ( $\square$ ).

Correlation of dextranase activity and chromophore production

A time course of the growth of thermophile Rt364 in Blue Dextran liquid medium was examined in relation to production of dextranase and the appearance of the yellow chromophore. Cells were inoculated into TYEBD $(13 \mathrm{ml})$. Cell growth was in $\log$ phase between $5-8 \mathrm{~h}$ but there was some lag in the production of dextranase, which began to appear at 7-8 h (Fig. 2). Maximum production of dextranase appeared at $25 \mathrm{~h}$. The yellow chromophore measured by the $A_{420}$ absorbance began to appear at $4 \mathrm{~h}$. The dextranase activity and cell growth correlated with the production of yellow chromophore. The amount of dextranase produced by anaerobic thermophiles, a maximum of $10 \mathrm{nmol} / \mathrm{ml} / \mathrm{min}$, is very low and the medium needs to be dialysed before assay. So this precludes enzyme measurement as a rapid screening procedure.

\section{Conditions necessary for production of yellow chromophore}

An experiment was undertaken to determine whether the production of the yellow chromophore required the presence of cells. Strain Rt56 grown on TYEBD for 7 days at $68^{\circ} \mathrm{C}$ turned yellow. A solution of Cibacron Blue (final concentration, $0.5 \%$ ) was injected into the spent yellow medium (see METHODs) and incubated at $68^{\circ} \mathrm{C}$ for 7 days. The medium did not change to a yellow color but remained blue 


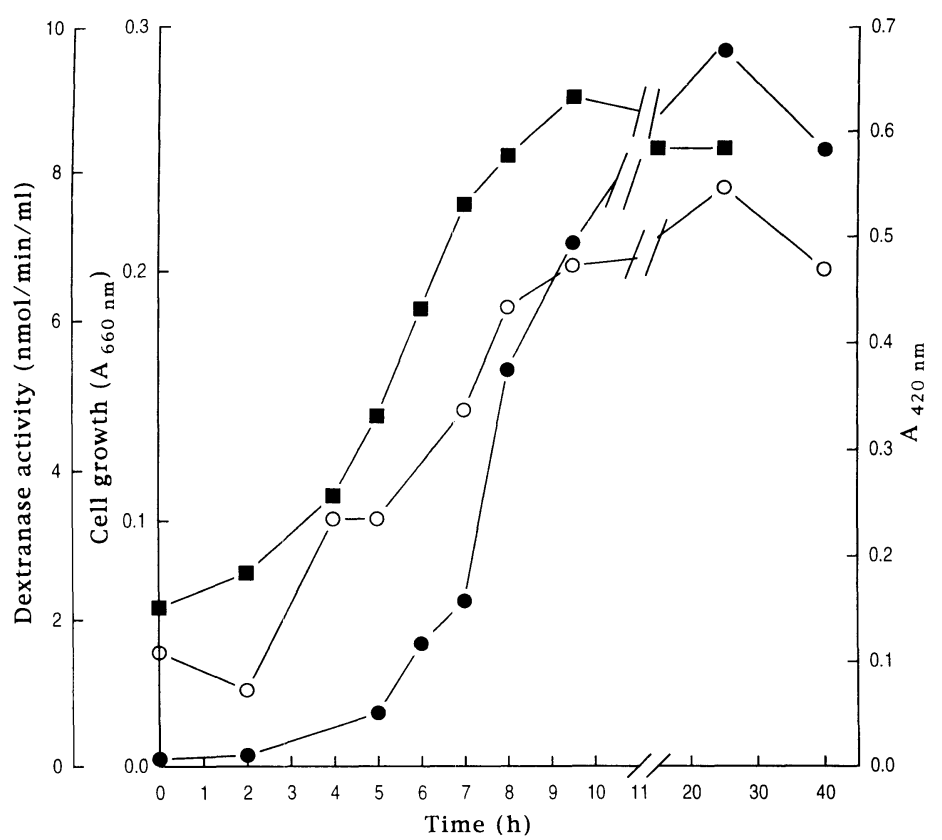

Fig. 2. Time course of cell growth and production of dextranase and yellow chromophore.

Growth of thermophile Rt364 at $68^{\circ} \mathrm{C}$ measured at $A_{660}(\boldsymbol{\square})$. Dextranase activity was assayed after dialysis of cell-free supernatant using the PAHBAH method (•). The $\boldsymbol{A}_{420}$ of the yellow chromophore in $70 \%$ ethanol (O).

Table 1. Production of chromophores in different media by the thermophilic bacterium Rt364 after growth for two days at $68^{\circ} \mathrm{C}$.

\begin{tabular}{llllll}
\hline Tube No. & \multicolumn{1}{c}{1} & \multicolumn{2}{c}{2} & \multicolumn{1}{c}{3} & \multicolumn{1}{c}{5} \\
\hline Cells & Active & Active & Resting & Resting & Active \\
Medium & TYEBD & TYE & LPBMS & LPBMS & TYEBD \\
Addition & None & Cibacron Blue & Cibacron Blue & Blue Dextran & Blue Trisacryl \\
Color & Yellow & Yellow & Blue & Yellow & Blue \\
$A_{420}$ & 1.33 & 2.09 & 2.1 & 0.59 & 0.05 \\
$A_{630}$ & 0.10 & 1.38 & 1.56 & 0.05 & $>2$ \\
\hline
\end{tabular}

due to the unconverted Cibacron Blue. This indicated that the anaerobic medium alone was not sufficient to cause the color change, but required the presence of cells.

In order to further define the conditions needed for production of the color change, actively growing cells of thermophile Rt364 were inoculated into a variety of anaerobic media according to the protocol in METHODS. The control (tube 1, Table 1) containing complete medium TYEBD with no additions gave the expected yellow color, high absorbance at $420 \mathrm{~nm}$ and low absorbance of the blue dye at 630 $\mathrm{nm}$. Tube 2 in which Blue Dextran was substituted by the dye Cibacron Blue, also 
turned yellow, indicating that the dye alone was metabolized by the actively growing cells of Rt364, giving a high $A_{420}$. The relatively high $A_{630}$ was due to the presence of some unconverted Cubacron Blue. Thus, the results are consistent with Cibacron Blue being metabolized in the same way as Blue Dextran fragments. In tube 3 (without dextran, tryptone and yeast but containing Cibacron Blue) the cells were not able to grow as there was no carbon source. The medium remained blue. In contrast, in tube 4 (without dextran, tryptone and yeast but containing Blue Dextran) the cells were able to utilize the Blue Dextran, grow and convert it to the yellow chromophore as seen by the decrease in $A_{630}$ and the increase in $A_{420}$. Therefore, actively growing cells were necessary for the conversion of Blue Dextran to the yellow chromophore. Cells which were autoclaved and added to TYEBD or LPBMS with Cibacron Blue (but no dextran) did not exhibit the color change in the medium and remained blue (data not shown).

Blue Trisacryl is a chromatography resin which has the same dye Cibacron Blue attached to acrylamide, which is not a substrate for dextranase. Cells secreting dextranase were incubated with Blue Trisacryl in order to see whether the degradation of the polymer (dextran or acrylamide) was essential for the production of the yellow color. Strain Rt 364 , after $25 \mathrm{~h}$ incubation on TYED at $68^{\circ} \mathrm{C}$, produced a dextranase activity of $5 \mathrm{nmol} / \mathrm{min} / \mathrm{ml}$ of supernatant. The same cells grown in TYEBD had a dextranase activity of $7.6 \mathrm{nmol} / \mathrm{min} / \mathrm{ml}$ and the medium changed color to orange/yellow. However where Blue Trisacryl $(0.5 \% \mathrm{w} / \mathrm{v})$ had been added to cells growing in TYEBD although the cells had produced dextranase at a rate of $4.8 \mathrm{nmol} / \mathrm{min} / \mathrm{ml}$, the medium remained blue. After the addition of $70 \%$ ethanol, there was no absorbance at $420 \mathrm{~nm}$ in the supernatant (tube 5, Table 1). The results demonstrated that the cells could not convert Cibacron Blue dye to the chromophore as it was not released from the acrylamide by dextranase. It was concluded that the action of dextranase was essential for the production of yellow chromophore from Blue Dextran.

It would appear that there are two enzymic processes occurring in the cells. One is the production and possible secretion of a dextranase which can break down the $\alpha-1,6$ polysaccharide backbone to release small oligosaccharide fragments attached to the dye and initiate the process. The other is thought to be an oxidation/reduction system under anaerobic conditions that can reduce or break open the benzene rings of the dye to produce a yellow derivative of Cibacron Blue (1). The chemical structure of the yellow chromophore was not investigated. Either one or both of the enzymic systems are attached to the cell membrane as there is no color change when fresh Cibacron Blue is added to the filtered culture medium. It might be possible for a bacterium to produce an enzyme that cleaved Cibacron Blue from the polysaccharide backbone at the point of attachment to the sugar, giving a false-positive result for the presence of dextranase. However, this limitation would apply to all screening methods that use Blue Dextran. 
Light microscopy of thermophiles in liquid Blue Dextran medium

Rt364 cells grown anaerobically in TYEBD were examined under a light microscope. The cells showed extensive chain formation but cell growth, as judged by absorbance at $660 \mathrm{~nm}$, was not inhibited by the production of free Cibacron Blue in the medium. When these cells were transferred to TYED (without Blue Dextran) the cells grew normally. It is interesting to note that Sugai et al. (11) found that Cibacron Blue dye is an inhibitor of cell separation after division and causes growth inhibition of strains of Bacillus, Micrococcus, Streptococcus and Lactobacillus. The mechanism of inhibition is unknown but the enzyme endo- $\beta-\mathrm{N}$ acetylglucosaminidase binds Cibacron Blue very tightly and is involved in dispersing cell clusters of Staphylococcus aureus (12). This is the first report that Cibacron Blue inhibits cell separation in anaerobic thermophiles.

\section{Screening of organisms with liquid Blue Dextran medium}

About 150 thermal water samples were screened in TYEBD. Of these, about 30 tubes showed a visual change in the medium from dark blue to green to yellow over time. These were selected for quantifying the relative amount of dextranase produced by the absorbance at $420 \mathrm{~nm}$ of the yellow chromophore. A selection of some of the results is shown in Table 2. By day 1, very little production of chromophore had taken place. By day 2 , significant color change could be detected in some organisms but there was a wide variation of results. By day 4, some of the best chromophore producers were beginning to fade and at day 7 , most of the samples gave the same absorbance of $0.8-0.9$ units. The absorbance readings at day

Table 2. Absorbance at $420 \mathrm{~nm}$ of the ethanol extraction of cell-free supernatants after growth of thermophilic cultures at $68^{\circ} \mathrm{C}$.

\begin{tabular}{|c|c|c|c|c|}
\hline $\begin{array}{c}\text { Water samples } \\
\text { /Strain }\end{array}$ & Day 1 & Day 2 & Day 4 & Day 7 \\
\hline $\mathrm{Rt} 364^{a}$ & 0.031 & 0.985 & 0.898 & - \\
\hline AB50 & 0.030 & 0.894 & 0.785 & 0.785 \\
\hline AB51 & 0.162 & 0.825 & 0.768 & 0.860 \\
\hline Rt44 & 0.033 & 0.622 & 1.262 & 0.777 \\
\hline $\operatorname{Rt} 56^{a}$ & 0.032 & 0.509 & 1.014 & 0.836 \\
\hline Rt4 & 0.032 & 0.477 & 0.800 & 0.808 \\
\hline AB41 & 0.024 & 0.373 & 0.775 & 0.996 \\
\hline AB8 & 0.033 & 0.250 & 0.895 & 0.893 \\
\hline $\mathrm{AB} 11 \mathrm{~A}^{a}$ & 0.027 & 0.217 & 0.767 & 1.142 \\
\hline AB39 & 0.031 & 0.178 & 0.749 & 0.895 \\
\hline AB30 & 0.031 & 0.150 & 0.945 & 0.886 \\
\hline AB9 & 0.037 & 0.116 & 0.799 & 0.081 \\
\hline B4 & 0.034 & 0.068 & 0.393 & 0.510 \\
\hline STER $^{a}$ & 0.032 & 0.063 & 0.157 & 0.424 \\
\hline AB55 & 0.030 & 0.041 & 0.542 & 0.883 \\
\hline CT $61^{a}$ & 0.031 & 0.040 & 0.073 & - \\
\hline
\end{tabular}

a Indicates a purified strain.

- not determined. 
2 enabled the strains to be ranked according to the amount and activity of their dextranases. Strain Rt364 had the highest reading on day 2, followed by water sample AB50 and AB51. Judging by the absorbances at $420 \mathrm{~nm}$ on day 2, samples B4 and AB55 and strains STER and CT61 had the lowest dextranase activity. It was evident from the values at day 7 that some dextranase activity was present in B4, STER and AB55.

\section{Aerobes}

The screening method was also tested on thermophilic aerobes. After growth in TYEBD at $55^{\circ} \mathrm{C}$, the medium remained blue, in contrast to anaerobes. On addition of ethanol, the soluble blue polysaccharide fragments due to dextranase activity could be measured at $630 \mathrm{~nm}$, the peak absorption of the dye. There was no fading of the dye on exposure to air. Thus, an increase in absorption at $630 \mathrm{~nm}$ gave a measure of the amount of dextranase produced under aerobic conditions. Screening of approximately 40 aerobic thermophiles yielded 6 positive strains. Screening of the same 40 samples at $68^{\circ} \mathrm{C}$ yielded no dextranase-producing strains.

\section{CONCLUSIONS}

Growth of anaerobic microorganisms in TYEBD and the subsequent conversion of fragments of the blue dye, Cibacron Blue, to a yellow chromophore can be used as a visual method of evidence of dextranase activity. Precipitation of unhydrolysed Blue Dextran in 70\% ethanol and measurement of the chromophore in the supernatant at $420 \mathrm{~nm}$ gives a direct measure of dextranase activity, making it a useful tool for an extensive and simple screening program. This is especially useful for thermophilic organisms where very little dextranase is produced and it is either difficult to assay or difficult for organisms such as Rt364 which do not grow well on high concentrations of agar. The method, slightly modified, can also be applied to thermophilic aerobic organisms. Although it was not tested, the method should be applicable to aerobic and anaerobic mesophilic organisms with the advantage, as opposed to BDA plates, that it can be quantitated.

On purification of the dextranase from Rt364, it was found that the enzyme was active against two substrates, amylose and dextran (C. Wynter, unpubl.). This dextranase was tentatively named an amylodextranase. So this method is also useful for screening for this new class of enzymes, the amylodextranases.

The financial assistance of the Sugar Research and Development Corporation of Australia for this research (Project Number SRI6S) is gratefully acknowledged.

\section{REFERENCES}

1) Adams, M. W. W., Park, J. B., Mukund, S., Blamey, J., and Kelly, R. M., Metabolic enzymes from sulfur-dependent, extremely thermophilic organisms. In Biocatalysis at Extreme Tempera- 
ture, ed. by Adams, M. W. W. and Kelly, R. M., American Chemical Society, Washington, D.C. (1992), p. 4-22.

2) Brock, T. D. and Freeze, H., Thermus aquaticus gen. n. and sp. n. a non-sporulating extreme thermophile. J. Bacteriol., 98, 289-297 (1969).

3) Dewar, M. D. and Walker, G. J., Metabolism of the polysaccharides of human dental plaque. 1. Dextranase activity of streptococci, and the extracellular polysaccharides synthesized from sucrose. Caries Res., 9, 21-35 (1975).

4) Fulcher, R. P. and Inkerman, P. A., Dextranase 1. Characterization of the enzyme dextranase for use in sugar mills. Proc. Queensl. Soc. Sugar Cane Technol., 43rd Conf., Cairns, Australia, p. 295305 (1976).

5) Hamada, S. and Slade, H. D., Biology, immunology and cariogenicity of Streptococcus mutans. Microbiol. Rev., 44, 331-384 (1980).

6) Inkerman, P. A., An appraisal of the use of dextranase. Proc. Int. Soc. Sugar Cane Technol., 17th Congr., Manila, Philippines, p. 2411-2427 (1980).

7) Koh, T. Y. and Khouw, B. T., A rapid method for the assay of dextranase. Can. J. Biochem., 48, 225-227 (1970).

8) Lever, M., A new reaction for colorimetric determination of carbohydrates. Anal. Biochem., 47, 273-279 (1972).

9) Mencier, F., Methode simple et rapide de mise en evidence des microorganismes producteurs de dextranase. Ann. Inst. Pasteur (Paris), 122, 153-157 (1972).

10) Staat, R. H., Gawronski, T. H., and Schachtele, C. F., Detection and preliminary studies on dextranase-producing microorganisms from human dental plaque. Infect. Immun., 8, 1009-1016 (1973).

11) Sugai, M., Akiyama, T., Komatsuzawa, H., Miyake, Y., and Suginaka, H., Cibacron blue 3G-A inhibits cell separation of gram-positive bacteria. Arch. Microbiol., 155, 199-210 (1991).

12) Sugai, M., Koike, H., Hong, Y.-M., Miyake, Y., Nogami, R., and Suginaka, H., Purification of a 51 Da endo- $\beta$-N-acetylglucosaminidase from Staphylococcus aureus. FEMS Microbiol. Lett., 61, 267-272 (1989).

13) Sun, J., Cheng, X., Zhang, Y., Yan, Z., and Zhang, S., A strain of Paecilomyces lilacinus producing high quality dextranase. Ann. N.Y. Acad. Sci., 542, 192-194 (1988).

14) Wynter, C. V. A., Galea, C. F., Cox, L. M., Dawson, M. W., Patel, B. K., Hamilton, S., De Jersey, J., and Inkerman, P. A., Thermostable dextranases: Screening, detection and preliminary characterization. J. Appl. Bacteriol., 79, 203-212 (1995).

15) Zeikus, J. G., Hegge, P. W., and Anderson, M. A., Thermoanaerobium brockii gen. nov. and sp. nov. A new chemoorganotrophic caldoactive, anaerobic bacterium. Arch. Microbiol., 122, 41-48 (1979). 